\title{
The VAT Technique" Teaching Oral Prophylaxis
}

\author{
Ajay Kakar* \\ Periodontist and Implantologist, India \\ *Corresponding Author: Ajay Kakar, Periodontist and Implantologist, India.
}

Received: April 01, 2020

Published: April 03, 2020

(C) All rights are reserved by Ajay Kakar.

\section{Teaching oral prophylaxis}

Teaching a patient oral prophylaxis may seem like an innocuous exercise but it is a most critical aspect in clinical dentistry. It is hardly given the importance it deserves. The purpose of this issue is to highlight its importance and present an effective technique for the same.

Dental therapy is a long complex treatment modality even in the simplest of cases. Once completed, it is very critical to ensure that the treatment lasts for a long number of years and serves the patient effectively while it lasts. This can only be achieved if oral hygiene is maintained impeccably by the patient.

The "Visual", "Auditory" and "Tactile" perceptions have to be addressed simultaneously.

It has been very well established that the primary cause of dental problems is plaque, a conglomerate of bacteria, bacterial by products and debris. Plaque formation is constant and starts almost immediately even after the most stringent Oral Prophylaxis therapy. Plaque if left undisturbed will mineralize and eventually convert into calculus. This calculus which strongly adheres on the tooth surface is impossible to remove without undergoing a scaling procedure. On the other hand the patient can always eliminate plaque by employing the correct oral hygiene measures.

Plaque can be removed by a number of techniques which are broadly divided into Mechanical and Chemical. Literature evidence clearly indicates that even though the chemical means are very useful and beneficial, they can only function as adjuncts to mechanical removal of plaque.

Mechanical plaque removal has been traditionally done with a variety of twigs of plants/trees which are rubbed on the tooth surface where the plaque develops. One of the most significant advances in preventing oral disease was the invention of the tooth brush.

A tooth brush can be defined as a mechanical device with a handle and a head which has bristles arranged in multiple rows. The toothbrush has evolved considerably from its original design. of course it still has a handle, a head and bristles. The bristles now are made of high quality nylon and are treated and mechanically finished to be more effective and can remove plaque without any trauma even at the microscopic level.

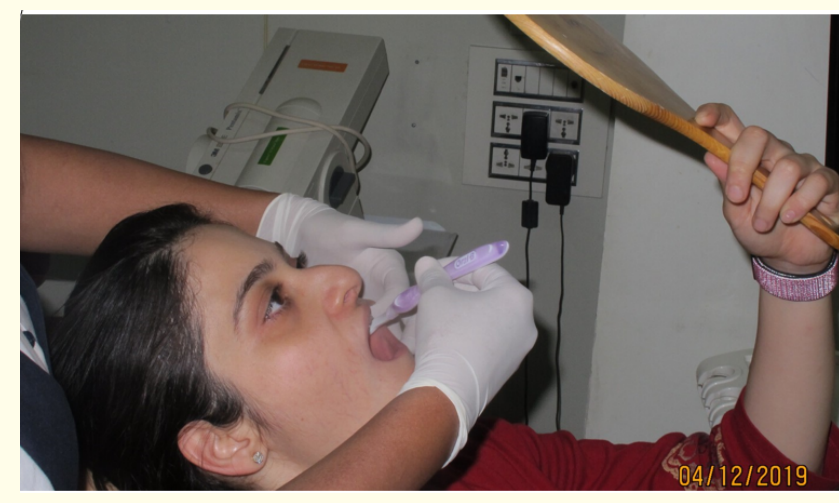

Figure 1

The tooth brush is usually used in conjunction with a tooth paste. The tooth paste acts as a lubricating agent, a mouth freshner and as a vehicle to carry molecules which act as an adjunct in plaque control. These molecules do not and cannot replace the mechanical removal of plaque. Hence they have been added to the toothpaste to help retard or block the reformation of plaque.

Since the toothbrush has to be used by the patient $t$ is quite evident that this means of plaque control is very heavily dependent upon the regular and proper usage of the brush.

Effectively and properly using the tooth brush for plaque control is not the simplest of procedures and nor is it the most difficult of procedures. The important aspect is that it is User Sensitive. This means that the regularity as well as the efficacy is completely dependent on the user. In fact this is what prompted the development of the power driven brush. The idea was that even if the patient is not using the brushing technique properly, the brush should be still able to remove all the plaque properly. Even though the power brush has been very heavily marketed, the regular hand brush today still remains the most widely used tool for daily plaque removal.

Hence is it extremely important and mandatory for the dentist to appropriately teach the patient how to use the tooth brush to maximum efficiency. It has been long established that the Modified Bass Technique is the most effective means of plaque removal. The objective is to impart to the patient all the details of how to employ the modified bass technique properly for the entire dentition. The 
other two aspects which are also very important is the duration and frequency of brushing.

A single session of brushing does not require more than 3 - 5 minutes. More than 5 minutes of hand brushing is overkill and not at all necessary. But the hurried brushing of about less than a minute or two is also not good enough for accessing all areas.

The frequency of brushing recommended is twice a day. Once is on getting up and the second is just prior to getting into bed.

Now for the technique. It is very important that the patient be relaxed and receptive for the training. The patient should be seated comfortably on the dental chair and should be given a hand mirror. The technique of training depends upon the three sensory stimulivisual, Auditory and Tactile-representing the acronym "VAT" technique. The mirror represents the "Visual" component of the triad. A new brush is necessary which will be used for the training and then given away to the patient. The dentist has to literally brush the patients teeth, albeit without an paste.

The modified bass technique has to be demonstrated on the maxillary and mandibular dentition. While showing the technique the dentist has to explain how the brush is used from gingival border to the incisal edge with a vibratory motion on the buccal and palatal/lingual surfaces and the occlusal surface.

The dentist provides the "Auditory" component and what the patient feels on the teeth is the "Tactile" component.

The technique demonstrated and taught is the Modified Bass Technique which is known to all the dentists but no patient is aware of it. It is imperative that the patient is spoken to in lay mans term, like outside surface of the teeth, the inside surface of the teeth and the biting surface of the teeth. The brush should be in the patients hand and the dentist should be holding the patients hand and guiding the patent how to move the brush on all the surfaces. It is best to make the patient access all the six involved surfaces. The three maxillary and the three mandibular surfaces.

First the maxillary buccal and then the maxillary palatal should be shown. It is not every surprising that most patients remark that they could never clean the buccal surfaces of the first and second molars in the maxilla. This is because of the curvature of the dentition and the difficult in accessing the hard to reach buccal surface of the second molar.

Another classical response is when the patient is shown the lingual of the lower anteriors. Most patient will often remark that they have never cleaned this area of the mouth component of the triad. A new brush is necessary which will be used for the training and then given away to the patient.

The dentist has to literally brush the patients teeth, albeit without a paste. The modified bass technique has to be demonstrated on the maxillary and mandibular dentition. While showing the technique the dentist has to explain how the brush is used from gingival border to the incisal edge with a vibratory motion on the buccal and palatal/lingual surfaces and the occlusal surface. The dentist provides the "Auditory" component and what the patient feels on the teeth is the "Tactile" component.

The lingual of the lower anteriors is a very difficult area to access. The curvature makes it a bit complicated to get the bristles down to the gingival margins. This is the reason that maximum calculus is found on the lingual of the lower anteriors.

It may be necessary that this demonstration be repeated after a couple of months to reinforce the importance of the technique. It is well worth the effort taken to teach oral prophylaxis with the VAT technique. Patients will have longer lasting dentitions and dental therapy will work well without failure.

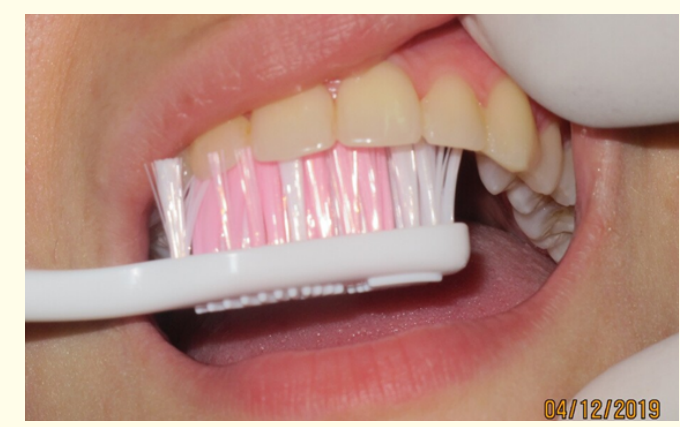

Figure 2

\section{Assets from publication with us}

- Prompt Acknowledgement after receiving the article

- Thorough Double blinded peer review

- Rapid Publication

- Issue of Publication Certificate

- High visibility of your Published work

Website: www.actascientific.com/

Submit Article: www.actascientific.com/submission.php Email us: editor@actascientific.com

Contact us: +919182824667 